\title{
Model Latihan Servis Sepak Takraw Kencang Dan Tajam untuk Atlet Pemula (Spike Serve Training Model For Beginner Athletes)
}

\author{
Dadang Budi Hermawan \\ Universitas Sebelas April \\ dadang_budi@unsap.ac.id
}

\begin{abstract}
Abstrak
Tujuan dari penelitian dan pengembangan ini menghasilkan model latihan Servis Sepak Takraw untuk atlet pemula di Kabupaten Sumedang. Selain itu, penelitian dan pengembangan dilakukan untuk memperoleh informasi secara mendalam tentang pengembangan dan penerapan model latihan, juga untuk mengetahui efektivitas, efisiensi model yang dibuat. Penelitian dan pengembangan ini menggunakan metode Research \& Development (R\&D) dari Borg and Gall. Sampel dalam penelitian ini ialah siswa dari Sekolah Menengah Pertama Negeri 1 dan 2 Conggeang Kabupaten Sumedang yang tergabung dalam club sepak takraw kabupaten Sumedang. Sebagai kebaruan dan temuan dalam penelitian ini sebuah variasi latihan beserta penciptaan sebuah alat bantu penghantar bola yang berfungsi guna membantu pelatih dalam melatih serta mempercepat peningkatan kemampuan atlet dalam mencapai kompetensi yang dituju, dalam hal ini adalah kompetensi servis sepak takraw. Guna mengetahui hasil dari penerapan model, peneliti menggunakan beberapa tes, yaitu uji efektifitas model menggunakan instrumen tes yang telah ditentukan sebelumnya. Analisis data penelitian menggunakan uji t dengan taraf signifikansi 0.05. Analisis data diperoleh nilai rata-rata keterampilan servis sepak takraw atlet sebelum diberikan model yang dikembangkan adalah 12,155 dan setelah diberikan perlakuan dengan model latihan yang dikembangkan, nilai rerata dari sampel sejumlah 50 atlet adalah 215,62 artinya model yang dikembangkan tersebut mengalami peningkatan. Dalam uji signifikansi perbedaan dengan IMB SPSS 21 For Windows dapat hasil t-hitung $=-111,387 \mathrm{df}=49$ dan $\mathrm{p}$-value $=0.00<0.05$ yang berarti terdapat perbedaan yang signifikan kemampuan servis sebelum dan sesudah diberikan perlakuan, bahwa model latihan servis sepak takraw untuk atlet pemula Kabupaten Sumedang. Berdasarkan keterangan tersebut dapat dikatakan bahwa model latihan untuk atlet pemula yang dikembangakan efektif dan dapat meningkatkan kemampuan servis sepak takraw.
\end{abstract}

Kata kunci: Model, Sepak Takraw, Latihan Servis, Atlet Pemula 


\begin{abstract}
The purpose of this research and development resulted in the Sepak Takraw Service training model for beginner athletes in Sumedang Regency. In addition, research and development is carried out to obtain in-depth information about the development and application of training models, as well as to determine the effectiveness, efficiency of the models made. This research and development uses research \& development $(R \& D)$ research methods from Borg and Gall. The samples in this study were students from the State Middle School 1 and 2 Conggeang Sumedang District. As a novelty and findings in this study a variety of exercises along with the creation of a ball delivery device that functions to help trainers in training and accelerating the increase in athletes' ability to achieve the intended competencies, in this case is sepak takraw service competence. In order to find out the results of applying the model, researchers used several tests, namely test the effectiveness of the model using predetermined test instruments. Analysis of research data using the t test with a significance level of 0.05. Data analysis obtained the average skill score of sepak takraw service for athletes before being given the model developed was 12.155 and after being given treatment with the developed training model, the mean value of a sample of 50 athletes was 215.62 meaning that the developed model had increased. In the test of significance difference with SPSS 21 IMB For Windows can the results of $t$-count $=-111,387 d f=49$ and $p$-value $=0.00<0.05$ which means there are significant differences in service ability before and after treatment, that sepak takraw service model for Sumedang Regency beginner athlete. Based on this information it can be said that the training model for beginner athletes who are developed is effective and can improve sepak takraw's service ability.
\end{abstract}

Keywords: Model, Sepak Takraw, Service Exercise, Beginner Athlete 


\section{Pendahuluan}

Pendekatan ilmiah yang bertujuan untuk meningkatkan prestasi telah diterapkan dalam olahraga. Penyiapan sumber daya manusia yang berkualitas merupakan langkah yang strategis untuk dikembangkan walaupun melibatkan berbagai unsur fisik seperti daya tahan, kecepatan, kekuatan, dan kelincahan sehingga tercipta atlet yang mempunyai kesegaran jasmani yang baik. Kesegaran jasmani merupakan komponen penting bagi setiap manusia untuk dapat hidup secara produktif dan mampu menyesuaikan diri terhadap kerja fisik pada setiap aktivitasnya. "Kesegaran jasmani adalah kondisi jasmani yang menggambarkan kemampuan jasmani, kemampuan seseorang untuk melakukan suatu pekerjaan tertentu dengan cukup baik, tanpa mengakibatkan kelelahan."(Widiastuti, 2015)

Peningkatan kesegaran jasmani dapat dilakukan dengan berbagai cara seperti "Kegiatan olahraga pendidikan; olahraga rekreasi dan olahraga prestasi, "Olahraga pendidikan adalah pendidikan jasmani dan olahraga yang dilaksanakan sebagai bagian proses pendidikan yang teratur dan berkelanjutan untuk memperoleh pengetahuan, kepribadian, keterampilan, kesehatan, dan kebugaran jasmani." Olahraga pendidikan di kenal dengan Pendidikan jasmani, Olahraga dan kesehatan (PJOK) menggunakan media aktivitas fisik untuk mencapai tujuan pendidikan secara keseluruhan. "Olahraga rekreasi adalah olahraga yang dilakukan oleh masyarakat dengan kegemaran dan kemampuan yang tumbuh dan berkembang sesuai dengan kondisi dan nilai budaya masyarakat setempat untuk kesehatan, kebugaran, dan kegembiraan."
Olahraga ini bersifat meningkatkan kesegaran jasmani manusia melalui aktivitas fisik yang dikemas dengan model-model permainan (games) atau out bond, jogging, bersepeda, permainan bola kecil dan bola besar tanpa disertai dengan target prestasi tertentu. "Olahraga prestasi adalah olahraga yang membina dan mengembangkan olahragawan secara terencana, berjenjang, dan berkelanjutan melalui kompetisi untuk mencapai prestasi dengan dukungan ilmu pengetahuan dan teknologi keolahragaan." Olahraga prestasi adalah puncak dari kegiatan fisik yang dilakukan oleh manusia.

Dampak olahraga akan terasa jika dilakukan dengan benar, sesuai dengan peersyaratan, dan aturannya. "Olahraga akan memberikan dampak yang positif pada sistem tubuh, bila pelakunya mengetahui secara baik dan benar, apa dan bagaimana penetapan dosis dan tata cara pelaksanaan olahraga, dan sebaliknya akan berdampak negatif, bila pelakunya tidak memahami prinsip-prinsip dasar olahraga, dosis yang adequate, yang sesuai dengan umur, jenis kelamin, dan tujuan."(Badriah,. 2011) Olahraga selain menjadi alat untuk meningkatkan kesegaran jasmani juga dapat menjadi alat untuk pemersatu bangsa dan menjadi bagian dari masyarakat serta salah satu dari kebutuhan jasmani yang penting bagi manusia. Dari sekian banyak cabang olahraga yang dapat menjadi bagian dari masyarakat adalah sepak takraw.

Permaian sepak takraw merupakan sebuah bentuk permaian yang dimainkan oleh dua regu dengan menggunakan bagian tubuh tetapi tidak boleh menggunakan lengan untuk memainkan bola. Pengertian sepak takraw adalah "Permainan yang 
didominasi oleh kaki yang memainkan bola takraw diatas lapangan seluas lapangan bulutangkis dan dipertandingkan antara dua regu yang saling berhadapan dengan jumlah pemain masing-masing 3 (tiga) orang" (Hanif, 2015). "Olahraga ini ibarat gabungan antara sepak bola dan bola voli, yang dimainkan dilapangan seukuran bulutangkis oleh dua tim yang terdiri atas tiga pemain disetiap timnya dengan sebuah jaring setinggi lima kaki memisahkan kedua tim tersebut dan setiap tim memliki kesempatan tiga kali menyentuh bola, yang dianyam, dengan menggunakan kaki, lutut, bahu, atau kepala sebelum menyebrangkan bola tersebut ke daerah permainan lawan" (Engel, 2008). Sepak takraw dimulai dengan tekong melakukan servis kemudian memainkan bola maksimal tiga kali sentuhan sampai bola jatuh di lapangan lawan.

\section{METODE}

Penelitian dilaksanakan di Club sepak takraw Kabupaten Sumedang dengan lokasi penelitian di GOR Desa Conggeang Kulon Kecamatan Conggeang Kabupaten Sumedang. Waktu yang diperlukan dalam penelitian riset dan pengembangan dengan mengacu langkah-langkah penelitian riset dan pengembangan Borg and Gall memerlukan waktu 3 (tiga) bulan lebih dengan rangkaian kegiatan sebagai berikut:
a) Analisis kebutuhan
b) Perencanaan pengembangan model
c) Pengembangan desain model latihan
d) Validasi pakar dan revisi model
e) Ujicoba kelompok kecil dan revisi
f) Ujicoba lapangan dan revisi
g) Uji efektivitas model

h) Produk buku pengembangan

Berikut subjek penelitian akan dipaparkan pada tabel dibawah ini,

Tabel 01. Profil Subjek

\begin{tabular}{|c|c|c|}
\hline $\begin{array}{l}\text { Total } \\
\text { Subjek }\end{array}$ & tansi & $\begin{array}{l}\text { Informan } \\
\text { Pelatih }\end{array}$ \\
\hline $\begin{array}{l}15 \text { orang } \\
\text { uji } \\
\text { kelompok } \\
\text { kecil } \\
50 \text { orang } \\
\text { uji } \\
\text { kelompok } \\
\text { besar } \\
30 \text { orang } \\
\text { Uji } \\
\text { efektifitas }\end{array}$ & $\begin{array}{l}\text { Club sepak } \\
\text { takraw } \\
\text { Sumedang } \\
\text { Club sepak } \\
\text { takraw } \\
\text { Sumedang } \\
\text { Club sepak } \\
\text { takraw } \\
\text { Sumedang } \\
\text { Club sepak } \\
\text { takraw } \\
\text { Sumedang } \\
\text { Club sepak } \\
\text { takraw } \\
\text { Sumedang } \\
\text { Club sepak } \\
\text { takraw } \\
\text { Sumedang }\end{array}$ & $\begin{array}{l}\text { 1. atlet } \\
\text { pemula } \\
\text { putra } \\
2 . \quad \text { Iin } \\
\text { Firmansyah } \\
\text { 3. Cece } \\
\text { Sumiarsa } \\
\text { 4. Yogi } \\
\text { Subarjah } \\
\text { 5. Indra } \\
\text { Setiawan } \\
\text { 6. Teguh } \\
\text { Rambo }\end{array}$ \\
\hline
\end{tabular}

Semua subjek dengan jenis kelamin laki-laki merupakan pelajar yang tercatat di Sekolah Menengah Pertama Negeri 1 dan 2 di Conggeang. Dengan informan sebagai penghubung antara peneliti dengan subjek tersebut adalah pelatih, pelatih asisten di Club sepak takraw Kabupaten Sumedang serta akademisi dari perguruan tinggi STKIP Sebelas April Sumedang. Club sepak takraw mewadahi pembinaan para atlet sepak takraw yang menyandang status sebagai satu-satunya Club olahraga Sepak Takraw di Kabupaten Sumedang yang dinaungi oleh PENGCAB PSTI Kabupaten Sumedang.

Konsep model yang dikembangkan dalam penelitian yang penulis lakukan adalah bentuk model- 
model latihan servis sepak takaw untuk pemula dengan batasan umur 12-13 tahun yang aktif berlatih di Persatuan Sepak Takraw Indonesia (PSTI) Kabupaten Sumedang. Pendekatan dalam penelitian ini menggunakan metode drill yang disusun dalam bentuk daerah sasaan servis.

Perencanaan dan penyusunan program latihan dibuat agar dapat memberikan petunjuk dan tuntunan yang jelas dalam pelaksanaan penelitian. Sehubungan dengan itu maka pengembangan model latihan servis sepak takraw yang akan disusun dan dikembangkan berupa modifikasi dan kreatifitas dalam bentuk latihan servis sepak takraw untuk pemula berusia 12-13 tahun. Sarana dan prasarana yang digunakan dalam pengembangan model latihan ini berupa modifikasi alat pengantar bola, cones, tali, dan sasaran. Penelitian pengembangan merupakan penelitian yang menghubungkan berbagai rancangan kerja dan pengembangan yang berorientasi pada produk. Pada penelitian pengembangan juga memiliki tujuan untuk mengembangkan pengetahuan, atau menghasilkan suatu produk di bidang pendidikan dan pelatihan. Adapun produk-produk yang dihasilkan dalam penelitian pengembangan antara lain materi-materi pelatihan pelatih, atlet, media pelatihan untuk memudahkan latihan, sistem pelatihan dan lain-lain

Menurut Sugiyono berpendapat bahwa "Terdapat produk-produk pendidikan seperti kurikulum yang spesifik untuk keperluan pendidikan tertentu, metode latihan, media latihan, buku ajar, modul, kompetensi tenaga kependidikan, sistem evaluasi, model uji kompetensi penataan ruang kelas untuk latihan tertentu dan lain-lain (Sugiyono., 2008) Pendekatan yang dipergunakan dalam penelitian ini adalah pendekatan kualitatif dan kuantitatif, yang merupakan suatu pendekatan untuk mencari jawaban dari masalah melalui rumusan masalah yang telah dirumuskan dalam bab I yaitu pengembangan model latihan servis pada atlet pemula. Hasil akhir penelitian ini adalah model latihan servis sepak takraw berupa desain latihan yang lengkap dengan spesifikasi produknya sekaligus menguji keefektifan dari model latihan yang dibuat, sehingga dapat meningkatkan keterampilan servis sepak takraw untuk pemula dan dapat juga digunakan sebagai pegangan dalam melatih.

Penelitian ini menggunakan model pengembangan Research \& Development $(R \& D)$ dari Borg dan Gall dengan alasan bahwa setiap tahapan dilakukan secara sistematis untuk menghasilkan produk, selanjutnya ada studi pendahuluan sebagai awal mengetahui permasalahan, selain itu terdapat uji coba produk agar diketahui efektivitasnya serta produk direvisi untuk disempurnakan.

Berikut ini penulis uraikan langkahlangkah penelitian Research \& Development $(R \& D)$ dari Borg dan Gal yang terdiri dari sepuluh langkah.

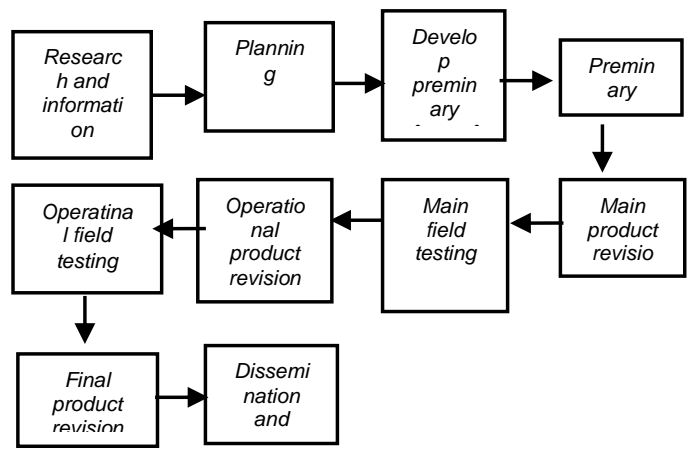

Gambar 1. Instructional Design $R$ and D 
Sumber: (Borg and Gall, 1983)

Langkah selanjutnya adalah tahapan-tahapan yang dilakukan dalam pengembangan model. Penelitian riset dan pengembangan model ini menggunakan langkah-langkah penyusunan model yang dikembangkan oleh Borg and Gall, langkah -langkah pengembangan modelnya tersebut meliputi:

1) Pertama kali yang ditentukan adalah Masalah atau potensi yang menjadi dasar pengembangan model

2) Selanjutnya dilakukan pengumpulan informasi sebagai landasan pemikiran untuk membuat konsep

3) Pembuatan model latihan (rancangan produk), bentuk rancangan tersebut adalah model latihan keterampilan servis sepak takraw.

4) Validasi desain, oleh para ahli,

5) Revisi, dari hasil uji ahli untuk validasi desain

6) Uji coba produkdengan mempraktekkan model latihan servis sepak takraw pada 15 subjek di uji kelompok kecil.

7) Ujicoba pemakaian atau uji kelompok yang lebih besar, dengan 50 subjek

8) Revisi hasil uji kelompok besar

9) Uji efektivitas pengembangan model

10) Model dapat diproduksi dalam bentuk buku

Untuk lebih jelasnya tentang langkah pengembangan model yang dilakukan peneliti adalah sebagai berikut. Analisis kebutuhan yang telah peneliti lakukan melalui observasi lapangan ketika proses latihan yang berlangsung di lapangan dan mengamatinya. Berdasarkan hasil observasi ditemukan seperti latihan servis masih kurang memperhatikan sistematisasi gerakan, yang penting bagaimana caranya bola bisa melewati net dan jatuh dilapangan lawan.

Semua rangkaian gerakan tersebut padahal sangat penting untuk dikuasai atlet pemula agar dapat mengembangkan rangkaian gerakan sesuai fungsi dari anatomi tubuh.

Bentuk latihan yang diberikan belum banyak menggunakan berbagai variasi, dampak negatif dari proses latihan yang kurang bervariasi adalah sebagai berikut.

1. kurang dapat mengembangkan teknik dasar servis sepak takraw dengan baik.

2. kurang memahami gerakan dan tujuan latihan teknik dasar servis sepak takraw.

3. kurang melakukan servis sepak takraw dengan berbagai sasaran.

4. pencapian hasil latihan servis sepak takraw kurang optimal.

Gerakan dasar yang salah akan menyulitkan untuk mengembangkan gerakan lanjutannya. Sebagai contoh ketika awal perkembangan sepak takraw di Sumedang latihan servis sepak takraw dilakukan secara beruntut seperti penulis jelaskan sebagai berikut.

1. hitungan pertama satu kaki (kaki tumpu) melangkan memasuki lingkaran dan kaki ayun berada di luar lingkaran;

2. hitungan kedua salah satu tangan meminta arah lambungan bola kepada apit sesuai yang diinginkan;

3. hitungan ketiga (kaki sepak) mengarahkan dan menendang bola hasil lambunga dari apit; 
4. Setelah menyepak bola gerak selanjutnya tubuh mengikuti gerak lanjutan.

Pada perkembangan sekarang pelatih mengajarkan servis sepak takraw pada pemula secara langsung bahkan dengan memaduak media latihan. Kelemahannya tekong pemula yang mulai belajar servis memiliki kesulitan dalam mempelajari dan mengarahkan bola hasil servis dengan menggunakan berbagai jenis servis. Berbeda dengan atlet yang pertama kali belajar servis sepak takraw secara beruntut, karena dengan penguasaan gerakan dasar tersebut, atlet lebih mudah untuk dikembangkan dalam mempelajari servis sepak takraw. Analisis kebutuhan yang telah dilakukan peneliti bermaksud untuk menerapkan model latihan servis sepak takraw untuk pemula di Club sepak takraw Sumedang.

\section{HaSil dan Pembahasan}

Berikut ini diuraikan hasil dari pembahasan model latihan Servis tajam (spike).

\section{Model latihan servis dengan media pengantar boladan rod}

\begin{tabular}{llr} 
Nama & \multicolumn{2}{l}{$\begin{array}{l}\text { Servis } \\
\text { (spike) }\end{array}$} \\
Tujuan & : & Memajam \\
& mampu melakukan \\
& servis kencang dan \\
& tajam & (spike) \\
& melalui & latihan \\
& dengan & media \\
& pengantar & bola \\
& (mesin DBH). \\
Sarana & Media pengantar \\
dan & bola, lapangan \\
prasarana & sepak takraw, Bola \\
& sepak takraw, Rod \\
& dan net.
\end{tabular}

Pelaksanaan:

Media pengantar bola (mesin $\mathrm{DBH}$ ) berada di lapangan yang disimpan diantara lingkaran tekong dan apit, rod dipasang di net (tinggi bentangan tali rod dari net bagian atas adalah $40 \mathrm{~cm}$ ).

\section{a. Model latihan 1.}

1. Media pengantar bola (mesin DBH) dihidupkan sehingga bola dapat dijatuhkan dari atas pengantar bola.

2. Tekong siap dilingkaran servis:

3. Pandangan kebola yang jatuh dari atas penyangga bola;

4. Putarkan kaki ayun kesamping depan dengan tungkai sedikit diluruskan;

5. Kenakan kaki ayun (kaki bagian dalam) kepada bola yang yang jatuh dari atas pengantar bola (dapat diulang-ulang untuk melatih bagian kaki dan ketepatan perkenaan kaki ayun dengan bola untuk menendang bola servis);

6. Pada saat kaki ayun menyentuh bola, pergelangan kaki dikencangkan;

7. Jatuhkan kaki ayun kedepan;

8. Posisi akhir badan menghadap ke net;

9. Bola hasil sepakan melintas diantara net bagian atas dan tali rod serta jatuh didaerah lapangan lawan;

Keterangan : Latihan ini dapat dilakukan dengan menggunakan kaki dominan maupun tidak dominan dan dilakukan secara berulang-ulang/Drills

$\begin{array}{lll}\begin{array}{l}\text { 2. Model latihan } \\ \text { berpasangan }\end{array} & \text { servis } \\ \text { Nama } & : & \text { Servis tajam (spike) } \\ \text { Tujuan } & : & \text { Memahami dan } \\ & & \text { mampu melakukan } \\ & \text { servis kencang dan } \\ & \text { tajam (spike) }\end{array}$


melalui latihan secara berpasangan.

Sarana dan : Lapangan sepak prasarana takraw, Bola sepak takraw dan net.

pelaksanaan

a. Model latihan 2 a.

Dibantu oleh teman yang berdiri disamping depan sambil Kaki tumpu berada didepan dengan sedikit ditekuk, sedangkan kaki ayun berada menyilang dibelakang kaki tumpu. Tangan (kiri) meminta datangnya bola, tangan kanan direntangkan untuk menjaga kesetimbangan. Urutan gerakan sebagai berikut.

1. Pandangan kearah bola yang akan dilempar teman;

2. Lengan kiri diluruskan kedepan untuk meminta agar bola dilambungkan oleh teman sesuai posisi tangan;

3. Lambungkan bola kepada tekong;

4. Putarkan kaki ayun kesamping depan dengan tungkai agak diluruskan;

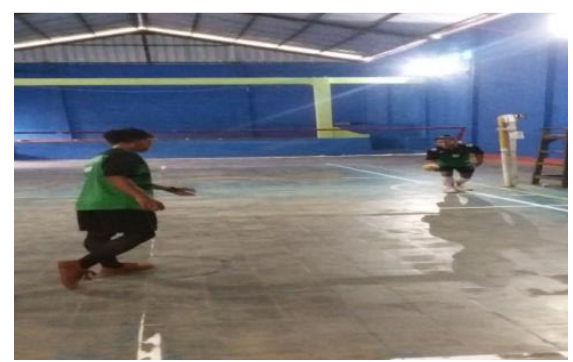

Gambar 02

Posisi awal tekong dan apit

5. Sepakan kaki ayun dengan kencang kepada bola yang dilambungkan oleh teman menggunakan kura-kura/punggung kaki;

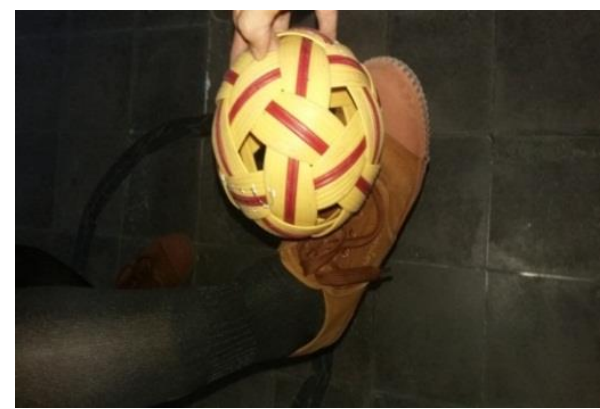

Gambar 03

Penggunaan punggung kaki/kurakura kaki

6. Pada saat kaki ayun menyentuh bola, pergelangan kaki dikencangkan

7. Jatuhkan kaki ayun ke depan kaki tumpu dengan telapak kaki tumpu agak jingjit;

8. Posisi akhir badan menghadap ke
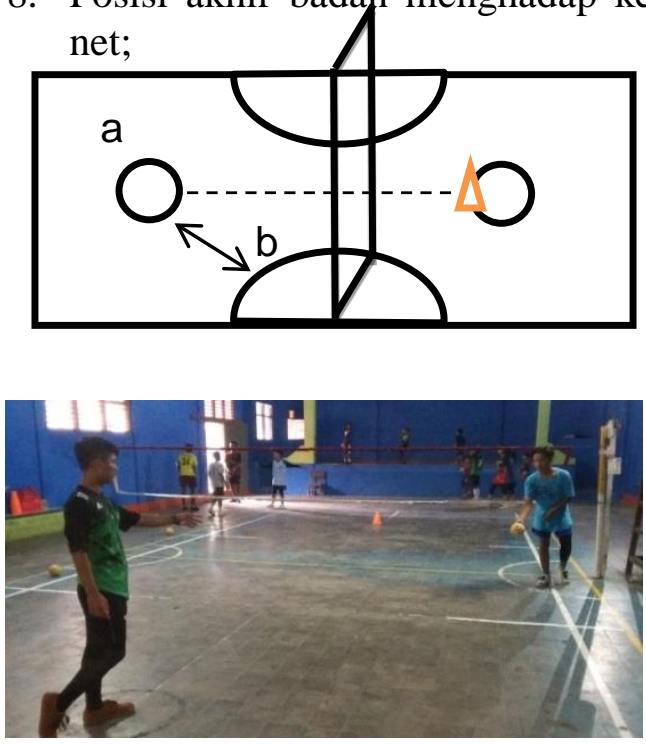

Gambar 04

Lay Out sasaran cones

9. Bola hasil sepakan diarahkan ke lapangan lawan sebanyak tiga kali.

b. Model latihan 2 b.

1. berdiri berhadap-hadapan dengan jarak 1,5m. 


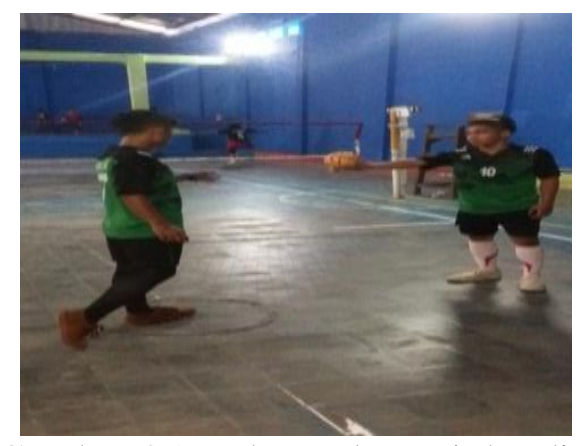

Gambar 05. Tekong dan apit berdiri dengan jarak 1.5 meter.

2. kedua subjek (atlet) berperan :

a. sebagai tekong,

b. sebagai apit

3. tekong bersiap di tempat :

a. kaki tumpu berada didepan kaki ayun $(40 \mathrm{~cm})$

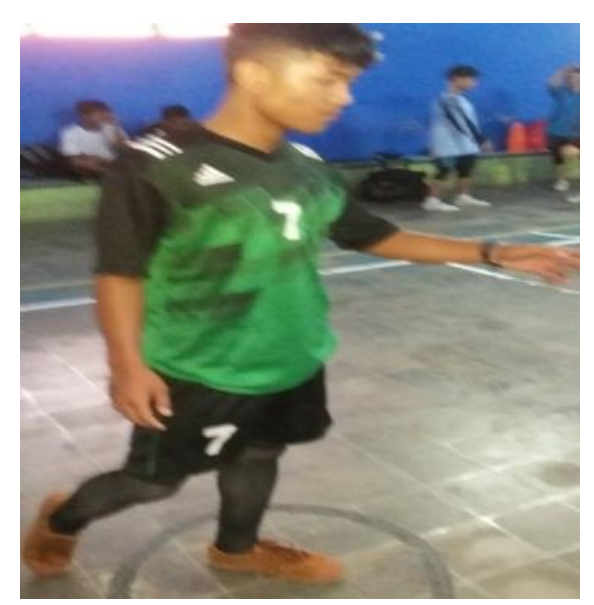

Gambar 06. Posisi tekong

b. posisi tangan diangkat sedikit lebih tinggi diatas rata-rata dada

c. ayunkan kaki ayun keatas (arah datang bola)

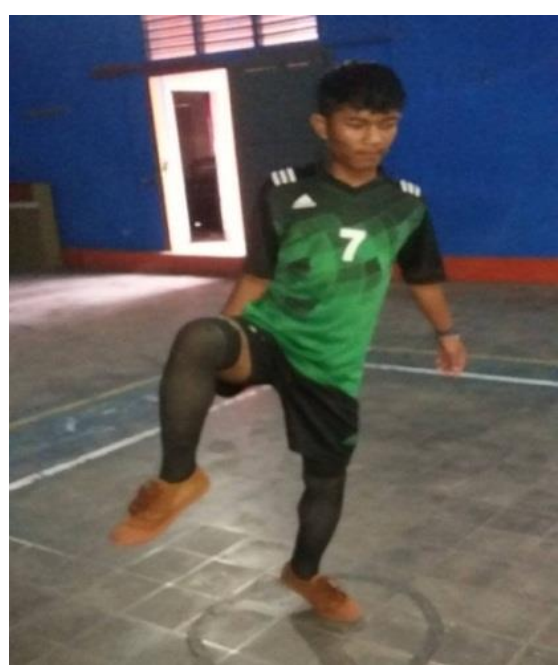

Gambar 07. Ayunkan kaki kearah datang bola

d. kencangkan pergelangan kaki dan lutut

4. saat apit melambungkan bola, sepak bola dengan kaki ayun dengan ayunan kaki kencang,

5. lakukan ayunan hingga perkenaan kaki ayun dengan bola, terjadi pada kaki bagian kura.

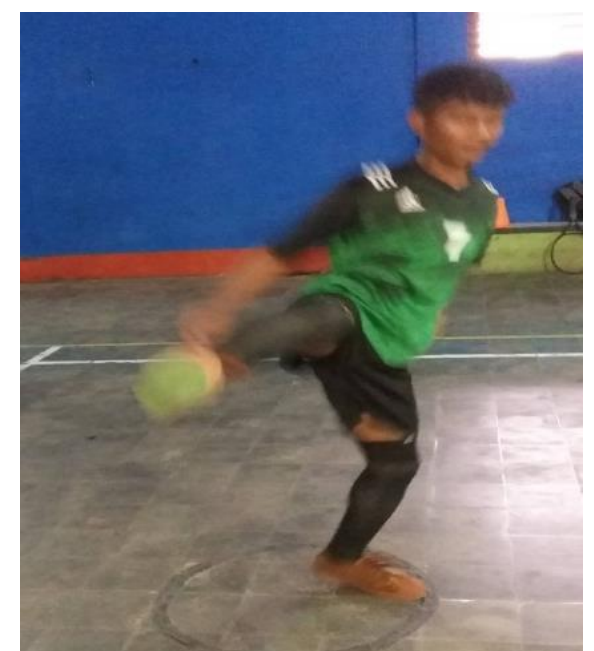

Gambar 08. Ayunkan kaki ayun dan sepak bola dengan menggunakan 
kaki bagian dalam.

6. Moment perkenaan terjadi pada saat jangkauan kaki ayun paling atas.

7. arahkan bola menukik tajam kearah langan lawan

8. Biarkan kaki ayun meneruskan gerakannya dan kembali mendarat sebagai gerak lanjutan (followtrough)

9. Lakukan 6x tembakan, kemudian saling berganti peran antara A Tekong dan B Apit.

Keterangan : Latihan ini dapat dilakukan dengan menggunakan kaki dominan maupun tidak dominan dengan secara berulang-ulang/Drills.

\section{Model latihan tekong beregu}

Nama : Sepak mula tajam (spike)

Tujuan : Memahami dan mampu melakukan sepak mula tajam (spike) melalui latihan secara beregu

Sarana dan : Lapangansepaktakraw, prasarana Bola sepak takraw, dan net.

pelaksanaan :

\section{a. Model latihan 3 a.}

1) berdirisalingberhadapan.

2) ketigasubjek (atlet) berperansebagai :

a. tekong : berdiri di lingkaran service

b. lawan : berdiri di lingkaran service lawan

c. apit : berdiri siap mengumpan bola pada tekong

3) tekong bersiap untuk melakukan service :

a. kaki tumpu berada didepan kaki ayun $(40 \mathrm{~cm})$, b. posisi tangan diangkat lebih tinggi diatas rata-rata dada,

c. ayunkan kaki ayun keatas (arah bola)

d. kencangkan pergelangan kaki dan lutut.

4) saat apit melambungkan bola, sepak bola dengan kaki ayun

5) perubahan kaki tumpu menjadi sediki diangkat (jinjit), dan badan condong kearah depan

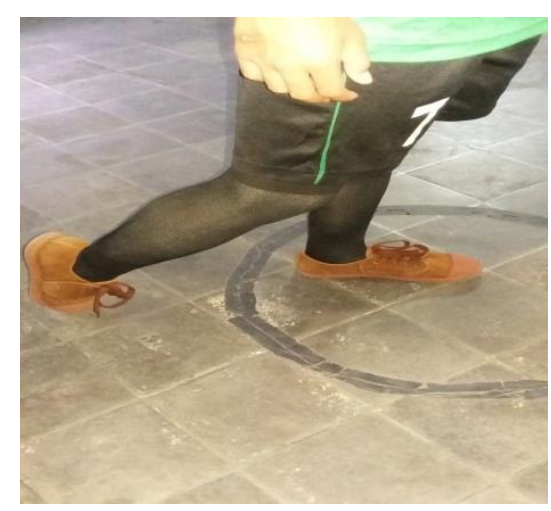

Gambar 09. Kaki ayun jinjit

6) sepak bola dengan menggunakan telapak kaki bagian dalam dengan kencang.

7) Biarkan kaki ayun meneruskan gerakannya dan kembali mendarat sebagai gerak lanjutan (followtrough)

8) arahkan bola kearah cones yang telah di tetapkan sebelumnya, yakni berada di lapangan lawan atau setidaknya bola mendekati cones.

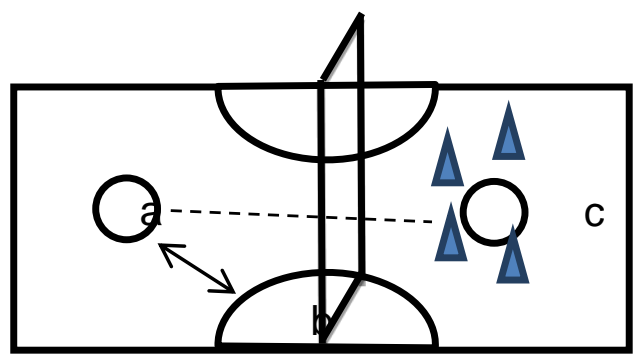




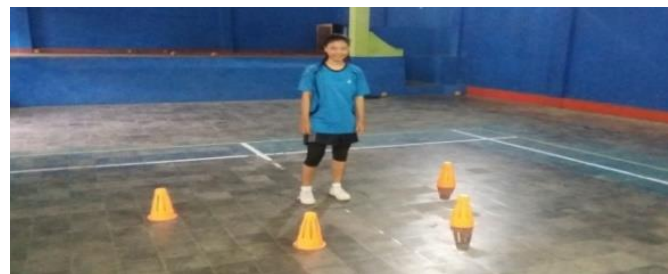

Gambar 10. Lay Outsasaran dan teman yang berdiri di lingkaran servis lawan

9) Untuk yang berperan sebagai lawan, berdiri di atas lingkaran servis lawan, dengan tujuan agar tekong mampu merefleksikan tekniksevis spike.

10) Tekong diberikan kebebasan memilih cones yang telah diletakan sebelumnya sebagai arah sasaran.

\section{b. Model latihan 3 b.}

Dibantu oleh seorang teman yang berdiri di lingkaran apit yang bertugas membantu melambungkan bola, dan satu orang berdiri di tengah-tengah garis akhir lapangan lawan. Tekong berada di lingkaran servis dengan kaki tumpu sedikit ditekuk dan berada di dalam lingkaran servis, sedangkan kaki ayun disilangkan kebelakang kaki tumpu. Tangan kiri digunakan untuk meminta arah bola yang dilempar oleh teman, tangan kanan direntangkan secukupnya disamping badan untuk menjaga kesetimbangan tubuh, pandangan ke arah datangnya bola yang dilempar oleh teman. Rangkaian gerakan sebagai berikut.

1. Tangan kiri meminta arah datangnya bola;

2. Lambungkan bola yang dipegang oleh teman sesuai permintaan tekong;

3. Ayunkan kaki ayun ke samping atas sampai kaki bagian kurakura/punggung kaki menyepak
4. bola yang dilambungkan oleh teman;

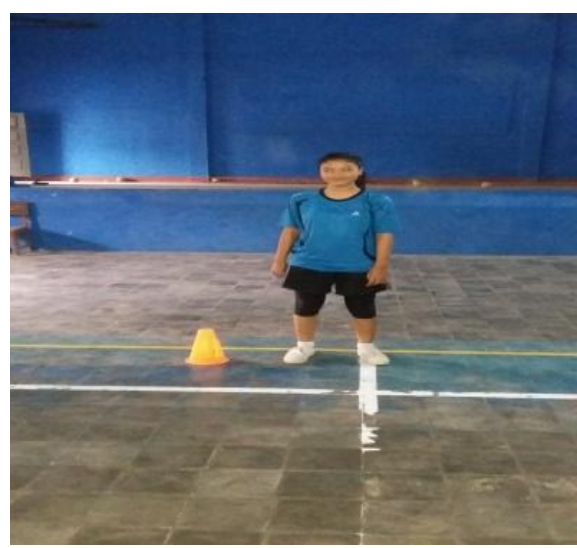

Gambar 11. Perkenaan bola padapunggung kaki

5. Ketika menyepak bola, pergelangan kaki dikencangkan, lutut diluruskan;

6. Moment perkenaan terjadi pada saat jangkauan kaki ayun paling atas dan dilakukan dengan kencang.

7. Jatuhkan kaki ayun kedepan setelah menyepak bola;

8. Pandangan ke arah laju bola;

9. Bola hasil sepakan jatuh di dekat garis akhir lapangan lawan yang sudah berdiri teman untuk menangkap bola kemudian dikembalikan kepada apit.

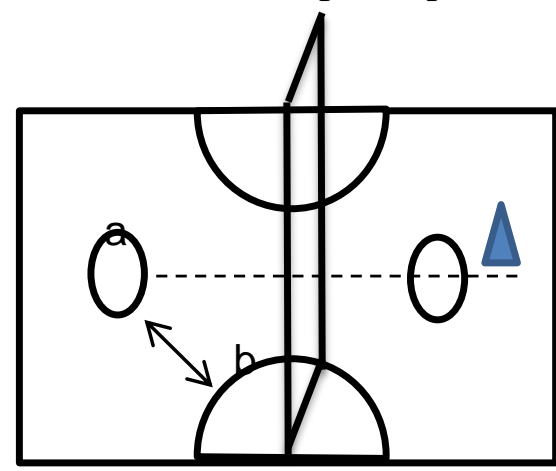

Gambar 12. Sasaran dan teman yang berdiri di garis akhir

10. Setiap tekong diberi kesempatan sebanyak lima kali. 
Keterangan :Target sasaran tembakan adalah cones atau tekong yang berada di lapangan lawan, lakukan secara bergantian dan gulirkan ketiga posisi hingga semua subjek (atlet) melakukan.

\section{Model latihan menggunakan} cones

$\begin{array}{ll}\text { Nama } & : \text { Sepak mula } \\ & \text { tajam (spike) } \\ \text { Tujuan } & : \text { Memahami dan } \\ & \text { mampu } \\ & \text { melakukan mula } \\ & \text { kencang dan } \\ & \text { tajam (spike) } \\ & \text { melalui latihan } \\ & \text { menggunakan } \\ & \text { sasaran cones }\end{array}$

Sarana dan : Lapangan sepak prasarana takraw, Bola sepak takraw, net, dan cones.

Pelaksanaan :

\section{a. Model latihan 4 a}

1. tekong berdiri diatas lingkaran service dengan posisi kedua kaki dibuka selebar bahu.

a. kaki tumpu berada di dalam lingkaran,

b. kaki ayun berada di luarlingkaran.

2. subjek (atlet) berbaris di belakang apit

3. tekong mengangkat tangannya tanda meminta arah diberikan bola.

4. saat apit melambungkan bola, tekong mengayunkan kaki ayun,

a. lutut serta pergelangan kaki di kencangkan,

b. perkenaan kaki dan bola menggunakan telapak kaki bagian dalam, dengan cara mengayun kaki ayun yang paling kencang dan lurus.

Gambar 13. Ayunan kaki ayun

5. arahkan bola pada cones (target) yg telah ditetapkan sebelumnya.

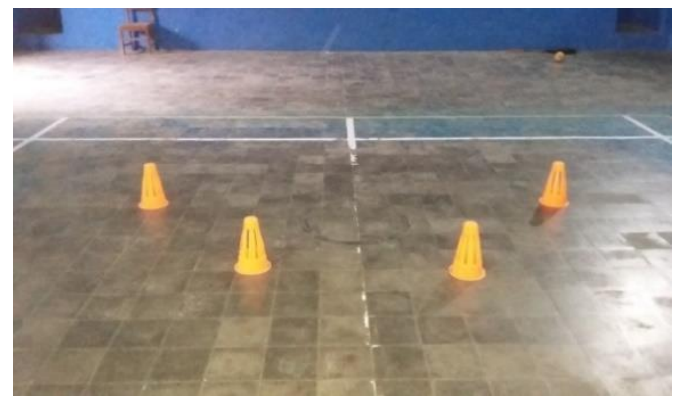

Gambar 14. Sasran cones

6. Arahkan sesuai dengan keinginan tekong

7. target (posisi cones) :

a. cones (1) $1 \mathrm{~m}$ samping kanan lingkaran lawan,

b. cones (2) $1 \mathrm{~m}$ samping kiri lingkaran lawan,

c. cones (3) 1,5m samping kiri lingkaran lawan,

d. cones (4) 1,5m samping kanan lingkaran lawan,

8) lakukan sepakan $3 x$ berturutturut serta arahkan pada sasaran (cones) secara acak. 


\section{b. Model latihan 4 b.}

Dibantu oleh seorang teman berdiri di lingkaran apit yang bertugas membantu melambungkan bola sebanyak enam (6) kali. Tekong berada di lingkaran servis dengan kaki tumpu sedikit ditekuk dan berada di dalam lingkaran servis, sedangkan kaki ayun disilangkan kebelakang kaki tumpu. Tangan kiri digunakan untuk meminta arah bola yang dilempar oleh teman, tangan kanan direntangkan secukupnya disamping badan untuk menjaga kesetimbangan tubuh, pandangan ke arah datangnya bola yang dilempar oleh teman. Rangkaian gerakan sebagai berikut.

1. Tangan kiri meminta arah datangnya bola;

2. Lambungkan bola yang dipegang oleh teman sesuai permintaan tekong;

3. Putarkan kaki ayun ke samping depan atas sampai punggung kaki/kura-kura kaki bagian dalam menyepak bola yang dilambungkan oleh teman;

4. Ketika menyepak bola dilakukan dengan keras/kencang, pergelangan kaki dikencangkan, tungkai sedikit diluruskan;

5. Jatuhkan kaki ayun kedepan kaki tumpu setelah menyepak bola;

6. Pandangan ke arah laju bola;

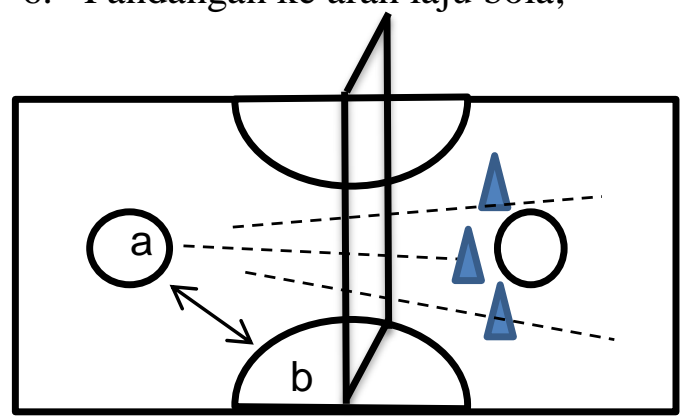

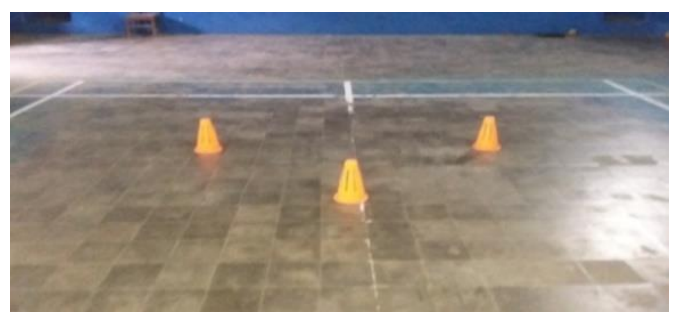

Gambar 15

Lay Out Lapangan dan sasaran cones

7. Tekong melakukan sepakan enam (6) kali berturut-turut dengan urutan:

a. Sepakan pertama (1) ke cones nomor satu (1)

b. Sepakan kedua (2) ke cones nomor dua (2)

c. Sepakan ketiga (3) ke cones nomor tiga (3)

d. Sepakan keempat (4) ke cones nomor dua (2)

e. Sepakan kelima (5) ke cones nomor satu (1)

f. Sepakan keenam (6) ke cones nomor tiga (3)

8. Bola hasil sepakan jatuh di lapangan lawan yang sudah ditandai oleh cones.

a. Cones pertama (1) disimpan di depan lingkaran servis dengan jarak dua (2) meter dari titik tengah lingkaran servis;

b. Cones kedua (2) disimpan arah serong kanan dari lingkaran servis dengan jarak satu koma lima (1.5) meter dari titik tengah lingkaran servis;

c. Cones ketiga (3) disimpan arah serong kiri dari lingkaran servis dengan jarak satu koma lima (1.5) meter dari titik tengah lingkaran servis.

Keterangan :Target sasaran tembakan adalah cones yang berada di lapangan lawan, lakukan secara bergantian dan 
gulirkan ketiga posisi hingga semua subjek (atlet) melakukan

\section{Model latihan dengan} permainan

$\begin{array}{ll}\text { Nama } & \text { Sepak mula } \\ \text { Tujuan } & \text { tajam (spike) } \\ & \text { Memahami } \\ & \text { dan mampu } \\ & \text { melakukan } \\ & \text { sepak mula } \\ & \text { kencang dan } \\ & \text { tajam (spike) } \\ & \text { melalui latihan } \\ & \text { dalam bentuk } \\ & \text { permainan } \\ \text { Sarana dan }: & \text { Lapangan } \\ \text { prasarana } & \text { sepak takraw, } \\ & \text { Bola sepak } \\ & \text { takraw, net, } \\ & \text { dan cones. }\end{array}$

Pelaksanaan :

\section{a. Model latihan 5 a.}

1. Subjek (atlet) dibagi menjadi beregu dengan jumlah per regu adalah 5 orang.

2. Setiap regu mendaftarkan regunya masing-masing untuk mengikuti turnamen (permainan).

3. Peraturan pelaksanaan :

a. Durasi permainan 15 menit per satu kali pertandingan.

b. Kapten dari masing-masing regu mengundi dengan cara lempar koin, untuk menentukan bola pertama permainan.

c. Bola hanya bisa di pantulkan (dimainkan) dengan teknik sepak mula tajam (spike) dan teknik sepak sila sebagai awal dari penerimaan bola awal.

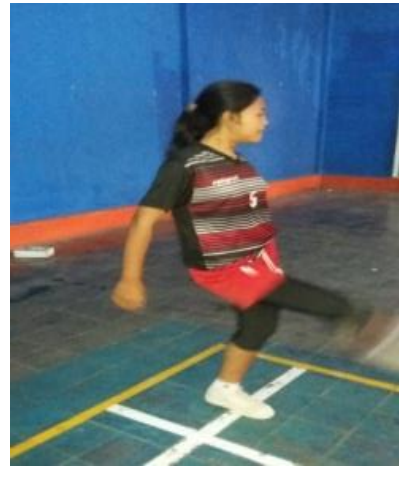

Gambar 16. Permainan dimainkan dengan sepak sila.

\section{b. Model latihan 5 b.}

Tekong dibagi menjadi dua (2) kelompok, masing-masing kelompok terdiri dari tiga (3) tekong. Perwakilan dari setiap kelompok kemudian melakukan toss/undian untuk menentukan kelompok mana yang melakukan servis terlebih dahulu. Rangkaian gerakan sebagai berikut.

1. Kelempok yang memenangkan toss/undian melakukan servis terlebih dahulu, dan dapat melakukan servis secara bergantian;

2. Tekong yang akan melakukan servis berdiri di lingkaran servis;

3. Kedua teman berperan sebagai apit yang berdiri di lingkaran apit kiri dan kanan untuk memberikan lambungan bola ke tekong;

4. Tekong melakukan sepakan dengan kencang/keras oleh kaki bagian dalam atau kura-kura/punggung kaki;

5. Arah bola hasil servis harus melewati net dan mengenai lawan yang sedang berdiri diam;

6. Kelompok yang tidak melakukan servis, berdiri bebas di daerah lapangan sendiri dengan posisi tidak mengindar/berpindah tempat jika bola hasil servis dari tekong lawan menghampirinya (bola ditangkap atau ditahan dengan sepak sila); 


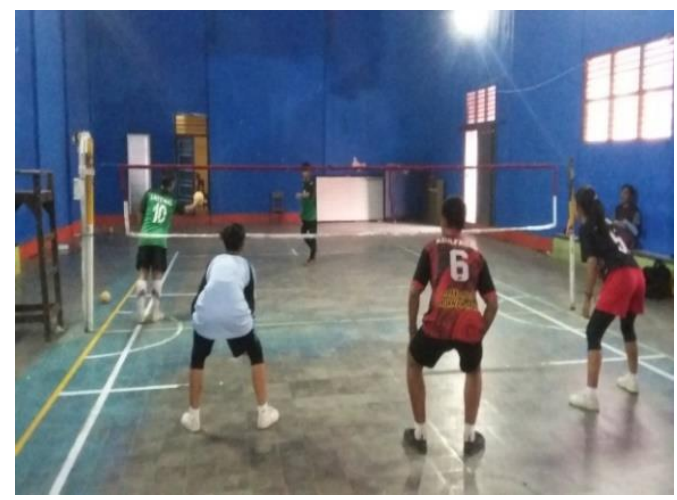

Gambar 17. Kelompok yang tidak melakukan servis berdiri bebas dilapangan sendiri

7. Jika bola hasil servis tekong lawan mengenai salah seorang anggota kelompok yang menerima servis maka harus keluar dan dinyatakan mati;

8. Jika salah satu kelompok tinggal satu orang, maka ketika melakukan servis harus melempar bola sendiri.

9. Servis dilakukan secara bergantian, setiap kelompok mendapat satu (1) kali kesempatan servis;

10. Kelompok yang telah keluar/mati semua anggotanya dinyatakan kalah.

Keterangan : lakukan pertandingan hingga semua regu ikut dalam permainan

6. Model latihan gerakan fisik

$\begin{array}{ll}\text { Nama } & \text { : } \\ & \text { Sepak mula } \\ \text { Tujuan } & \text { tajam (spike) } \\ & \text { Memahami dan } \\ & \text { mampu } \\ & \text { melakukan } \\ & \text { sepak mula } \\ & \text { kencang dan } \\ & \text { tajam (spike) } \\ & \text { dengan gerakan } \\ & \text { yang baik dan } \\ & \text { benar melalui } \\ & \text { latihan fisik }\end{array}$

$\begin{array}{lll}\text { Sarana } & : \text { Lapangan sepak } \\ \text { dan } & \text { takraw, } & \\ \text { prasarana } & & \end{array}$

Pelaksanaan :

a. Model latihan 6 a.

1. Tekong berdiri di lingkaran servis menghadap net dengan kaki tumpu, sedangkan kaki ayun berada dibelakang kaki tumpu

2. Ayun-ayunkan kaki ayun depan atas sebanyak dua kali delapan (2x8) hitungan.

3. Kemudian melakukan menayunayunkan kaki ayun kesamping atas sebanyak dua kali delapan (2x8) hitungan.
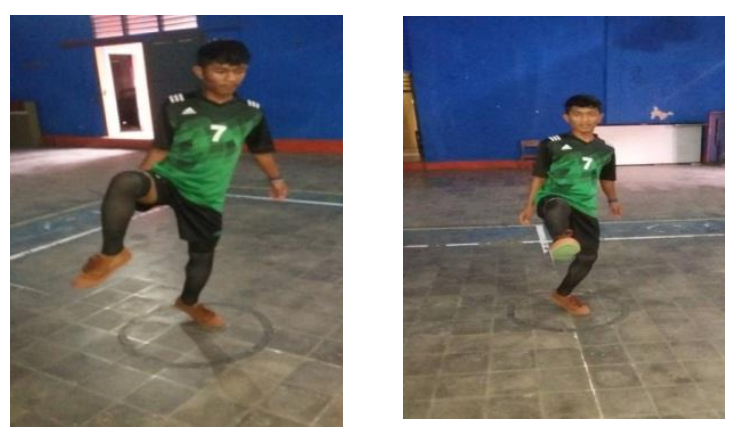

Gambar 18. Ayunan kaki ayun ke depan dan kesmping.

4. Gerakan selanjutnya tekong bersedia untuk melakukan sevis yang dibantu oleh apit yang melambungkan bola.

5. Bola hasil servis harus kencang/keras ke tengah lapangan lawan dengan menggunakan punggung kaki.

6. Tekong diberi tiga kali kesempatan melakukan servis.

\section{b. Model latihan 6 b.}

1. Tekong berdiri digaris akhir lapangan menghadap lapangan, kemudian berjalan ke arah lingkaran servis; 
2. Setelah tekong berada di lingkaran servis, kemudian melakukan jumping dengan kedua kaki sampai lutut menyentuh dada sebanyak tiga kali;

3. Setelah melakukan jumping dengan kedua kaki, tekong bersiap siap untuk melakukan servis;
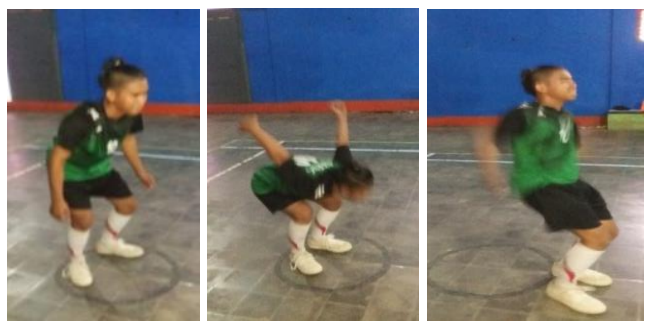

Gambar 19. Tekong melakukan jumping

4. Dengan bantuan dari teman pada di posisi apit yang melambungkan bola, tekong melakukan servis.

5. Bola hasil servis harus kencang/keras ke tengah lapangan lawan dengan menggunakan kurakura/punggung kaki.

6. Tekong diberi tiga kali kesempatan melakukan servis.

Keterangan : lakukan kedua gerakan tersebut berulang-ulang/drill

Dalam uji signifikansi perbedaan dengan program IMB SPSS 21 For Windows dapat hasil t-hitung =$111,387 \mathrm{df}=49$ dan $\mathrm{p}$-value $=0.00<$ 0.05 yang berarti terdapat perbedaan yang signifikan kemampuan servis sebelum dan sesudah diberikan perlakuan.
Tabel 2. Uji Signifikansi Perbedaan

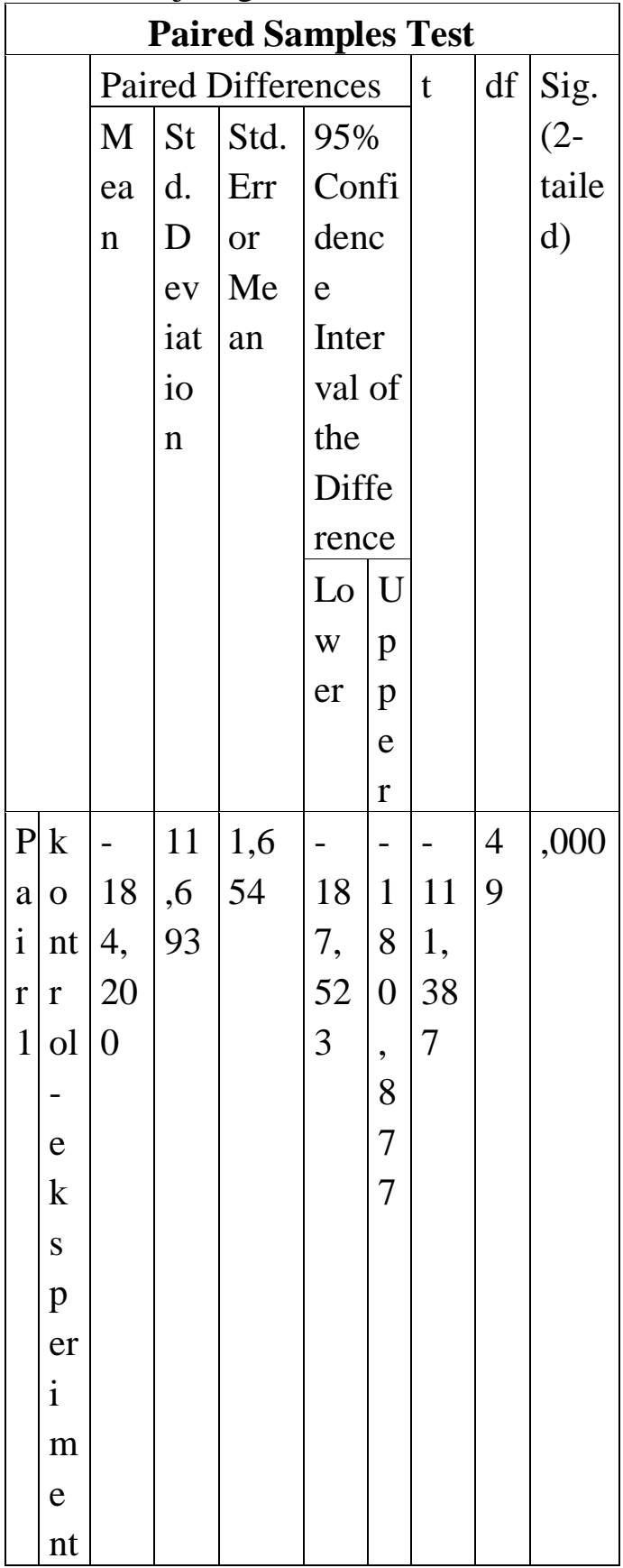

Berdasarkan keterangan tersebut dapat dikatakan bahwa model latihan untuk atlet pemula yang dikembangakan efektif dan dapat meningkatkan kemampuan servis sepak takraw. 


\section{IV.KESIMPULAN DAN SARAN}

A. Kesimpulan

1. Model latihan servis sepak takraw Kencang Tajam dapat diterapan sehingga terjadi peningkatan kemampuan servis sepak takraw atlet pemula di Club sepak takraw Kabupaten Sumedang.

2. Model latihan servis sepak takraw Kencang Tajam telah teruji dan memiliki nilai efektif dan dapat meningkatkan kemampuan servis sepak takraw atlet pemula sehingga model latihan servis sepak takraw Kencang Tajam dapat dan layak digunakan dalam latihan servis sepak takraw atlet.

B. Saran

Produk penelitian ini adalah materi kemampuan servis sepak takraw yang ditujukan pada pemula. Model latihan dapat digunakan dalam kegiatan latihan dan membentuk kemampuan yang lebih baik lagi serta, dalam memanfaatkannya sangat perlu dipertimbangkan situasi, sarana dan prasarana.

\section{DAFTAR PUSTAKa}

Engel, Rick . 2008. Dasar-Dasar Sepak Takraw instruksi lengkap/Panduan Melatih Sepak Takraw Jakarta:Pakaraya.

Hanif, Achmad Sofyan . 2015. Kepelatihan Dasar Sepak Takraw Jakarta: RajaGrafindo Persada

UU Sistem Keolahragaan Nasional No. 3 Tahun 2005 Pasal

Sugiyono, 2008. Metode Penelitian Pendidikan Pendekatan Kuantitatif, Kualitatif dan $R \& D$ Bandung: Alfabeta, 2008

Walter R. Borg and Meredith D. Gall, 1983. Educational Research: An Introduction, $4^{\text {th }}$ Edition. New
York: Longman Inc.

Widiastuti, 2015. Tes dan Pengukuran

Olahraga .Jakarta: Rajawali Pers. 